\title{
New Era of Management for Diabetes and Hypertension
}

Keywords: Type 2 diabetes mellitus; Hypertension; Guideline; Metabolic syndrome; American College of Physicians

\author{
Abbreviations \\ T2DM: Type 2 Diabetes Mellitus; Met-S: Metabolic Syndrome; \\ ACP: American College of Physicians
}

\section{Editorial}

Looking back on the history of medical care, noteworthy diseases have changed along with long history. For recent years, metabolic syndrome (Met-S) has been increasing all over the world, which is an important health, medical and social problems [1,2]. Its prevalence has been higher in developed countries so far [3]. Nowadays, however, there has also been an increase in developing countries and appropriate action has been strongly needed.

Basically, the pathophysiology of Met-S has been insulin resistance and impaired regulation of lipid metabolism is also associated [4-6]. Among them, the genetic predisposition is a factor of Met-S, and the prevalence of Met-S differs depending on the ethnic group [7]. For example, the HDL gene has strong relevance and may be inherited by $70 \%$ [8]. Furthermore, several factors have affected by lifestyle habitual factors, age, socioeconomic status, and so on [9].

Regarding the frequency of Met-S, results somewhat differ depending on diagnostic criteria. However, the prevalence of Met-S has been increasing more and more in both developed and developing countries [9]. As a standard or average estimation, the prevalence in adults seems to be about 20-25\% worldwide [10]. As Met-S has increased rapidly, the prevalence of type 2 diabetes, hypertension, cardiovascular disease, obesity have also increased in parallel [11].

Metabolic syndrome includes obesity as a fundamental pathophysiological status, and also hypertension, diabetes, dyslipidemia, and so on. Among them, in this article I would like to introduce several recent findings on hypertension and diabetes.

As to hypertension, its frequency is high around the world. Various guidelines have been announced in each area or country. Regarding hypertension and heart disease, guidelines have been announced in Europe [12,13], North America and in Japan [14-16]. Furthermore, there are guidelines on young generation and the elderly, lipid and obesity, which also covers widely relating to hypertension and heart disease [17-20].Therefore, treatment of hypertension will be necessary to comprehensively utilize each guideline for management.

When hypertensive patients are treated, antihypertensive drugs are not given from the beginning. It is important to start correcting or adjusting lifestyle at first. For hypertension and high blood pressure, treatment and care other than drug administration have been conventionally called "non-drug therapy". In addition to patients who have been already diagnosed and suffering from hypertension,
Advances in

Diabetes \& Endocrinology

\section{Hiroshi Bando* \\ Tokushima University and Medical Research, Japan}

*Address for Correspondence

Hiroshi Bando, Tokushima University and Medical Research, Nakashowa 1-61, Tokushima 770-0943, Japan, Tel: +81-90-3187-2485, E-mail: pianomed@ bronze.ocn.ne.jp

\section{Submission: 07 May 2018}

Accepted: 14 May 2018

Published: 21 May 2018

Copyright: $\odot 2018$ Bando H. This is an open access article distributed under the Creative Commons Attribution License, which permits unrestricted use, distribution, and reproduction in any medium, provided the original work is properly cited.

there are many subjects in preclinical stage of hypertensive tendency. Such people must be considered for healthier life from the viewpoint of first prevention of hypertension at the preclinical stage [21].

There was a guideline for hypertension presented in 2017. It was High Blood Pressure Clinical Practice Guideline as A Report of the American College of Cardiology/American Heart Association Task Force on Clinical Practice Guidelines. As for nonpharmacological Interventions, it recommended 6 possible preventive or treatable factors. They are weight loss [22], a heart-healthy diet such as the DASH (Dietary Approaches to Stop Hypertension) diet [23], sodium reduction [24], potassium supplementation [21], increased physical activity and reduction in alcohol consumption [25].

There is a report on the withdrawal of antihypertensive medicine at a Japanese clinic which is specific to hypertension [26]. There are thousands of cases of hypertension annually, among which the percentage of antihypertensive drugs that could be withdrawn was 4.6\%-6.1\% over the last few years. Among them, 50 cases in which antihypertensive drugs were discontinued ( 25 cases in both males and females) were examined. As a result, the family history of hypertension was 33 cases (66\%) in women, smoking in men was 76\%, alcohol consumption in men was $60 \%$, besides $42 \%$ for dyslipidemia and $12 \%$ for type 2 diabetes. Usually, it can be judged that $12 \%$ seems to be low as compared with the prevalence of diabetes in patients with hypertension.

One reason for this would be that there are microangiopathy and macroangiopathy due to the complication of diabetes. Consequently, it may be related to the existence of impaired function of blood vessel. In other words, it is presumed that improvement of blood pressure control is not easy due to vascular disorders developed by the influence of diabetes.

Furthermore, examining the six cases (12\%) out of 50 cases, it was characterized that the body weight was reduced by $2.8 \mathrm{~kg}$ on average by improving the meal and lifestyle habits. Therefore, it seems that there is a relation with the significant improvement of the condition of diabetes. 
Up to this point, recent trend and research results of hypertension was described. Subsequently, development of guideline for diabetes will be shown. The main purpose and target of diabetes therapy is the prevention of complications [27]. For years, the endpoint of many clinical trials is to lower blood glucose levels, but intensive treatments aimed at lowering the $\mathrm{HbA} 1 \mathrm{c}$ to less than $6.5 \%$ are often accompanied by hypoglycemia as a side effect. At the same time, intensive regimens have not shown a reduction of cardiovascular complications in the long-term [28-32]. For example, the action to control cardiovascular risk in diabetes (ACCORD) trial was prematurely discontinued, following the observation of an increase in overall mortality, cardiovascular-related deaths, and severe hypoglycemic events [28].

Regarding the process of diabetes guidelines, comments have been made from different positions in each country and each organization. In the United States, there were some guidelines and statements on diabetes guidelines, including the American Diabetes Association (ADA), the American Society of Clinical Endocrinology, and the American Endocrine Society (AACE/ACE). However, there was a difference in the contents, and confusion was actually seen in the clinical setting.

Therefore, the Clinical Guidelines Committee of the American College of Physicians (ACP) independently evaluated several guidelines, and released a statement on ACP's own HbAlc management goal. ACP is an authoritative conference and highly reliable for years. Unlike ADA and AACE / ACE guidelines, the statement of ACP is extremely shocking, with a management goal of type 2 diabetes patients under medication of $7 \%$ to $8 \% \mathrm{HbAlc}$ [33].

Prior to presentation, ACP examined the guidelines for the existing HbAlc management objectives of six academic organizations. They included AACE / ACE, ADA, the Institute for Clinical Systems Improvement (ICSC), the UK National Clinical Evaluation laboratory (NICE), Scottish University guideline network (SIGN), US Department of Veterans Affairs and US Department of Defense guidelines (VA / DoD) [34-39].

Furthermore, these studies were based on 5 well-known previous mega studies, including 1) UKPDS 33, 34, 2) UKPDS 80, 3) ACCORD 4) ADVANCE, 5) VADT associated with lots of reliable data accumulation.

As described above, there have been some transition in guidelines for hypertension and diabetes. Further development will be expected by accumulation of medical treatment and clinical research in the future.

\section{References}

1. Lim S, Eckel RH (2014) Pharmacological treatment and therapeutic perspectives of metabolic syndrome. Rev Endocr Metab Disord 15: 329-341.

2. Mendonca FM, de Sousa FR, Barbosa AL, Martins SC, Araujo RL, et al (2015) Metabolic syndrome and risk of cancer: which link? Metabolism 64 182-189.

3. Ranasinghe $P$, Mathangasinghe $Y$, Jayawardena R, Hills AP, Misra A (2017) Prevalence and trends of metabolic syndrome among adults in the asiapacific region: a systematic review. BMC Public Health 17: 101

4. Reaven GM (1988) Role of insulin resistance in human disease. Diabetes 37 : 1595-1607.

5. DeFronzo RA, Ferrannini E (1991) Insulin resistance. A multifaceted syndrome responsible for NIDDM, obesity, hypertension, dyslipidemia, and atherosclerotic cardiovascular disease. Diabetes Care 14:173-194.

6. Reaven GM (1995) Pathophysiology of insulin resistance in human disease. Physiol Rev 75: 473-486.

7. Ford ES, Giles WH, Dietz WH (2002) Prevalence of the metabolic syndrome among US adults: findings from the third national health and Nutrition Examination Survey. JAMA 287: 356-359.

8. King RA, Rotter JI, Motulsky AG (2002) Approach to genetic basis of common diseases. Oxf Monogr Med Genet 44: 3-17.

9. Cornier MA, Dabelea D, Hernandez TL, Lindstrom RC, Steig AJ, et al. (2008) The metabolic syndrome. Endocr Rev 29: 777-822.

10. International Diabetes Federation (2006) The IDF consensus worldwide definition of the metabolic syndrome pp: 1-34.

11. Zimmet P, Alberti K, Shaw J (2001) Global and societal implications of the diabetes epidemic.Nature 414: 782-787.

12. Perk J, De Backer G, Gohlke H, Graham I, Reiner Z, et al. (2012) European guidelines on cardiovascular disease prevention in clinical practice (version 2012). The fifth joint task force of the european society of cardiology and other societies on cardiovascular disease prevention in clinical practice (constituted by representatives of nine societies and by invited experts). Eur Heart J 33: 1635-1701.

13. Mancia G, Fagard R, Narkiewicz K, Redon J, Zanchetti A, et al. (2013) 2013 $\mathrm{ESH} / \mathrm{ESC}$ guidelines for the management of arterial hypertension: the task force for the management of arterial hypertension of the european society of hypertension (ESH) and of the european society of cardiology (ESC). Eur Heart J 34: 2159-2219

14. Goff DC Jr, Lloyd-Jones DM, Bennett G, Coady S, D'Agostino RB, et al. (2014) 2013 ACC/AHA guideline on the assessment of cardiovascular Risk. a report of the american college of cardiology/american heart association task force on practice guidelines. Circulation 129: 49-73

15. Whelton PK, Carey RM, Aronow WS, Casey DE Jr, Collins KJ, et al. (2017) ACC/AHA 2017 High blood pressure clinical practice guideline.Guideline for the prevention, detection, evaluation, and management of high blood pressure in adults.

16. JSH (2014) The task force for the management of hypertension of the Japanese society of hypertension (JSH) and $\mathrm{JSH}$ guideline for the management of hypertension 2014. pp: 1-248.

17. Lurbe E, Agabiti-Rosei E, Cruickshank JK, Dominiczak A, Erdine S, et al. (2016) 2016 European society of hypertension guidelines for the management of high blood pressure in children and adolescents. J Hypertens 34: 18871920.

18. The Japan Geriatrics Society (2017) the Japan geriatrics society guidelines for the management of elderly hypertension 2017. J Jap Geriat Soc 54: 236237.

19. Authors/Task Force Members:, Catapano AL, Graham I, Backer GD, Wiklund O, et al. (2016) 2016 ESC/EAS guidelines for the management of dyslipidaemias the task force for the management of dyslipidaemias of the european society of cardiology (ESC) and european atherosclerosis Society (EAS) developed with the special contribution of the european association for cardiovascular prevention \& rehabilitation (EACPR). Atherosclerosis 253: 281-344.

20. Jensen MD, Ryan DH, Apovian CM, Ard JD, Comuzzie AG, et al. (2014) 2013 AHA/ACC/TOS guideline for the management of overweight and obesity in adults: a report of the american college of cardiology/american heart association task force on practice guidelines and the obesity society. Circulation 129:102-138.

21. Whelton PK (2015) The elusiveness of population-wide high blood pressure control. Annu Rev Public Health 36:109-130.

22. Neter JE, Stam BE, Kok FJ, Grobbee DE, Geleijnse JM, et al. (2003) Influence of weight reduction on blood pressure: a meta-analysis of randomized controlled trials. Hypertension 42: 878-884 
23. Kaye EK, Heaton B, Sohn W, Rich SE, Spiro A, et al. (2015) The dietary approaches to Stop hypertension diet and new and recurrent root caries events in men. J Am Geriat Soc 63: 1812-1819.

24. Aburto NJ, Ziolkovska A, Hooper L, Cappuccio FP, Meerpohl JJ, et al. (2013) Effect of lower sodium intake on health: systematic review and metaanalyses. BMJ 346: 1-20.

25. Inder JD, Carlson DJ, Dieberg G, McFarlane JR, Hess NC, et al. (2016 Isometric exercise training for blood pressure management: a systematic review and meta-analysis to optimize benefit. Hypertens Res 39: 88-94.

26. Bando M, Fujiwara I, Imamura Y, Takeuchi Y, Hayami E, et al. (2018) Lifestyle habits adjustment for hypertension and discontinuation of antihypertensive agents. J Hypertens (Los Angel) 7: 249.

27. Ojo O (2016) An overview of diabetes and its complications. Diabetes Res Open J 2: e4-e6.

28. ACCORD Study Group, Gerstein HC, Miller ME, Genuth S, Ismail-Beig $F$, Buse JB, et al. (2011) Long-term effects of intensive glucose lowering on cardiovascular outcomes. N Engl J Med 364: 818-828.

29. Advance collaborative group, Patel A, MacMahon S, Chalmers J, Billo L, Woodward M, et al. ( 2008) Intensive blood glucose control and vascular outcomes in patients with type 2 diabetes. N Engl J Med 358: 2560-2572.

30. Duckworth W, Abraira C, Moritz T, Emanuele N, Reaven PD, et al. (2009). Glucose control and vascular complications in veterans with type 2 diabetes. N Engl J Med 360: 129-139.

31. UKPDS (1998) Effect of intensive blood-glucose control with metformin on complications in overweight patients with type 2 diabetes (UKPDS 34). UK
Prospective Diabetes Study (UKPDS)Group. Lancet 352: 854-865

32. Hayward RA, Reaven PD, Wiitala WL, Bahn GD, Reda DJ, et al. (2015). Follow-up of glycemic control and cardiovascular outcomes in type 2 diabetes. N Engl J Med 372: 2197-2206.

33. Qaseem A, Wilt TJ, Kansagara D, Horwitch C, Barry MJ, et al. (2018) A1c targets for glycemic control with pharmacologic therapy for nonpregnant adults with type 2 diabetes mellitus: a guidance statement update From the american college of physicians. Ann Intern Med 168: 569-576.

34. Handelsman Y, Bloomgarden ZT, Grunberger G, Umpierrez G, Zimmerman $\mathrm{RS}$, et al. (2015) American association of clinical endocrinologists and american college of endocrinology - clinical practice guidelines for developing a diabetes mellitus comprehensive care plan - 2015. Endocr Pract 1: 1-87.

35. American Diabetes Association (2017) Glycemic Targets. Sec. 6. In Standards of medical care in diabetes-2017. Diabetes Care 40: S48-S56.

36. Redmon B, Caccamo D, Flavin P, Michels R, Myers C, et al. (2014) Institute for clinical systems improvement (ICSC). Diagnosis and management of type 2 diabetes mellitus in adults. pp: 1-83.

37. NICE (2015) Type 2 diabetes in adults: management. National Institute for Health and Care Excellence.

38. Scottish Intercollegiate Guidelines Network (SIGN) (2017) Management of diabetes. A national clinical guideline. Healthcare Improvement Scotland. pp. $1-143$.

39. Department of veterans affairs (2017) Department of defense. VA/DoD clinical practice guideline for the management of type 2 diabetes mellitus in primary care pp: 1-34. 